\title{
Overconsumption, Procreation, and Morality
}

John Mariana (College of the Canyons, Santa Clarita, California, United States)

\section{Introduction}

In an intriguing but mostly overlooked essay, Thomas Young (2001) attempts to defend the claim that procreation and overconsumption are morally equivalent, and thus that whatever moral judgment we believe applies to one applies to the other. Specifically Young means to show that to the extent that one condemns overconsumption (for any number of reasons) but finds procreation acceptable or even laudable, then one holds an inconsistent set of moral convictions, and in particular he targets those whom he calls "mainstream environmentalists" as being guilty of such inconsistency (Young 2001, 183). ${ }^{1}$ So his audience is, by his own admission, fairly narrowly specified, and indeed he further restricts his ambitions in the essay by refusing to attempt a full defense of any specific implication of the claim of moral equivalence. He says that his primary interest is in the analogical argument he presents in support of the equivalence claim - which claim, for convenience, I shall call ME - and that though he finds refraining entirely from procreating to be "the lesser of two evils" (the two evils being on the one hand giving up having children, and on the other hand lowering the quality of life for all through environmental degradation), his support of this position "will be brief, for [his] main concern was to expose a bedrock inconsistency in mainstream environmentalism, not to defend a particular option (that is, a particular set of consistent beliefs)" (Young 2001, 190).

But the implications of ME are surely more sweeping than Young is interested to acknowledge, and the modesty of his proposal seems feigned. If ME is true, then even those who see nothing wrong in what Young calls overconsumption must accept that procreation is morally legitimate only to the extent that it entails the legitimate overconsumption of resources. This makes Young's analogy far more contentious than he makes it seem. Considering how much importance he places on the analogy alone, it's curious that his support of it is so glib and hasty. I shall argue that Young's case for ME does not succeed. I

\footnotetext{
${ }^{1}$ I do not take this claim to be meant as a demographically or sociologically or politically accurate generalization -viz., that people who would identify themselves as, or who are (by some definition), "mainstream environmentalists" do as a rule hold such a set of beliefs - but merely as a means of designating the people Young has in mind. Young's usage here is surely strategic, but whether his use of this terminology for this purpose is fair or accurate will not be among my concerns here.
} 
believe that his support for the equivalence claim could be much stronger than it is, and I will suggest some ways in which Young's claims could be more effectively defended, as well as explain why I think they are worth serious reflection. But I shall also argue that, in the end, this reflection leads to the conclusion that ME cannot be supported with the kinds of moral-theoretical resources Young deploys.

\section{Young's Analogy}

First I should explain how Young attempts to defend ME. As I have said, his basis for the equivalency claim is analogical. In fact, he sets up his argument with a thought experiment involving two hypothetical families: the Greens and the Grays. The Greens, as you've probably guessed, have no children and are not planning on having any and are average Americans who consume at an average American rate and level. The Grays have two children, or plan to, but in all other respects are identical to the Greens in terms of resource consumption. By having two children, the Grays will increase their total resource-consumption footprint by two-and-a-half times. For the Greens to match the Grays without children they would have to increase their consumption by an equivalent amount, which would mean overconsumption. And since the motives for and effects of both choices are essentially the same, procreation and overconsumption are morally equivalent.

So that this isn't all just abstract theorizing, Young refers at this point to another intriguing paper by Hall et al. (1994), titled "The Environmental Consequences of Having a Baby in the United States," for hard scientific data to quantify exactly what counts as "average" American consumption at 1990 levels, and thus what would count as overconsumption - which he defines as any consumption that exceeds the average. On this basis he is able to cash out the concept of overconsumption in a numerically precise way, so at least he isn't open to the charge of vagueness or of vacuity (that overconsumption (excessive consumption) is simply any amount of consumption that would be morally blameworthy). But of course this has both the advantages and the disadvantages of exactness, and it raises is/ought problems that Young would clearly prefer to avoid.

Even if you don't count yourself an environmentalist, you're probably wondering why average American consumption isn't itself, by definition, overconsumption. After all, as Hall clearly shows, the average American consumes more than 300 times the average of people in some other parts of the world. ${ }^{2}$ But then these are places where the people - by our standards - are either desperately poor or adhere to a pre-industrial form of life. So on what

2 Hall (1994) quantifies not only average American consumption, but average consumption elsewhere in the world, to provide a basis for comparison. 
basis are we to say that any group of people overconsume? Isn't any rate of consumption thus relative and not absolute? Ultimately the numbers game is not just a trick to make Young's argument sound scientific. We can say that a group of people overconsume relative to the total availability and quantity of resources at a given time; and, as is well known by now, Americans consume annually more than a quarter of the energy produced worldwide, though we represent only a small fraction of the world's population (less than 10\%) (Assadourian et al. 2004, 11). This makes average American consumption exceedingly demanding on global resources. From a morally neutral, numerical point of view, however, rates of consumption are relative. We could say in a purely numerical sense that even the average American overconsumes relative to some baseline level of average consumption for the rest of the world, or for the majority of its population.

But of course the question whether a rate of consumption 300 times the average rate in say, Sri Lanka, is excessive in any moral sense depends on both the consequences of the framework of production and consumption that includes this disparity and on the even trickier issue of whether the average Sri Lankan (or whoever) is capable of consuming enough to have a reasonably high quality of life. Of course a judgment of overconsumption - what Young rather non-neutrally calls "eco-gluttony" - also implies a moral judgment, and not simply a metrical assessment of the relative usage of goods produced to the size of a given population. On this point Young is content to simply stipulate: any rate of consumption that exceeds the average American rate we shall call, for the purposes of this argument, "overconsumption." He is also content to simply appeal to the moral intuitions of his target audience. If you're inclined to be tolerant of the average American rate of consumption, but you think that consumption beyond (or much beyond) this level is excessive and bad (or even wrong), then ME shows that you must apply the same judgment to procreation. All of this will prove significant later on.

Before we move forward, there's just one other little wrinkle to address, which you're probably also wondering about. Even if you're not a mathematician you're probably wondering why the Grays would increase their consumption two and a half times by having two children, and not just two times. Two people, two units of consumption. So, four people, four units of consumption, right? And, for that matter, how come the Gray children count toward their parents' consumption?

At this point Young makes a fairly obvious (though very important) observation which will also prove significant. His observation is this: the existence of children, and thus of the additional consumption they will represent, is (generally) a direct result of the conscious choices of their 
parents. ${ }^{3}$ Thus, your rate of consumption is calculated as a combination of your own consumption plus the total lifetime consumption of your children. (If we wanted to really lay on the guilt and the sense of overwhelming moral responsibility, we should note that Young's claim here, if true, would imply that you are also responsible for your children's children's consumption, or at least for the portion of it that you will live to subsidize as grandparents and as coinhabitants of the planet.) Again for convenience, I shall call this claim that parents are morally responsible for their children's existence and resource consumption MR.

From ME and MR Young derives the calculation that the Grays would increase their consumption two and a half times by having two children. If two 30 -year-olds represent 50 more years of consumption apiece, and their two children represent 80 years apiece, or 160 years total, then that's 100 years of consumption plus 160 years, or 260 years, which is just over five times the average single adult unit; hence, 2.5 times the consumption of two people $5=$ $(2.5)(2))$. Again Young is playing the numbers game; of course all of these are averages. And he doesn't seem to take the effects of co-habitation into account that members of the same household tend to share resources (one vacuum and one lawnmower for four or more people, say, instead of just for two) - though perhaps these effects would be relatively negligible.

Following his development of the analogy, Young attempts to defend it through an assessment and rejection of a variety of potential dissimilarities between procreation and overconsumption that would undermine the comparison. Obviously the claim most in need of defense here is that the motives and effects involved in both activities are really all that's morally relevant. On the face of it this claim doesn't seem especially plausible. The immediately apparent difference between procreation and overconsumption is that the one activity results in the existence of more people and the other results merely in the consumption of additional stuff. To say that the motives underlying these activities and the effects that they produce are all that's morally relevant would seem to imply that, morally speaking, there's no significant difference between bringing someone into existence and buying a couple of private jets, which over the course of a lifetime may involve about the same quantity of resource consumption and depletion. Of course, this is precisely the sort of objection Young anticipates.

He considers and dismisses four possible dissimilarities between procreation and overconsumption, which he labels A through D. They're not

3 Of course this claim could be challenged, and it would be worth knowing how many children of those that are born each year are unplanned (and perhaps why and under what circumstances). This isn't necessarily a quibble, but I'm going to ignore it for the remainder of my discussion. Ultimately my criticisms of Young will not in any important way depend on the answer to this question. 
entirely independent of one another, but he does what he can to separate lines of counter-argument that might otherwise get run together. Among them they represent what would seem to be the most obvious and the most decisive objections to the analogy, and Young leaves few stones unturned. To summarize, the dissimilarities are: that procreation is less selfish than overconsumption (A); that having children is a greater source of happiness than overconsumption (B); that procreation is a basic moral right (C); and that procreation involves bringing into existence new beings with inherent worth or value (D). Each of these could have received better and fuller treatment than Young gives them, most especially $\mathrm{C}$, but this is not my main concern. In discussing some problems with Young's handling of these dissimilarities I will be building up to a larger criticism of Young's argumentative strategy as a whole.

\section{The Analogy Defended}

Young dispatches Dissimilarity A fairly quickly. He observes that "the claim that a consumer lifestyle exceeding that of the average American is usually more selfish than raising a family must be successfully defended, which is unlikely. Clearly, many people have children for primarily selfish reasons: to continue genetic lines, to gain an illusory sense of immortality, to revive a marriage, to minimize loneliness in old age, to feel profoundly wanted, and so on" (Young $2001,187)$. Young seems to have forgotten the wording of his own imagined objection. The question is not whether procreation can or does (sometimes or often) involve selfish motives, but whether overconsumption is more selfish than procreation. I suppose this would be difficult to establish, but then this reveals an ambiguity in Young's interpretation of the objection, and suggests a stronger formulation of it.

Though Young is ostensibly concerned with the moral dimensions of procreation and overconsumption as activities (if you will), he shifts between what are essentially sociological and statistical observations (which he suggests are either imprecise or inconclusive) and dubious claims of non-quantifiability, as it suits his argument. From what standpoint should we evaluate whether one sort of activity involves more or less selfish motives than another? We could begin by taking a poll, the point of which would, I suppose, be to discover empirically, as a matter of psychological fact, whether people who overconsume generally tend to be selfish people. But what would that show? The moral question is whether, as a kind of activity, procreation involves more selfishness than overconsumption. Young also notes that an overconsuming couple "might have a dozen jet-skies, six jacuzzies [sic], three bars, and an indoor tennis court so guests will enjoy themselves" (Young 2001, 186). But again, the question is not whether overconsumers can be selfless in their overconsumption, but whether overconsumption is more selfish as an activity 
than procreation. Ultimately Young concludes by discounting motivation as having any substantial bearing on our moral assessment of people's actions as permissible or impermissible. ${ }^{4}$ His example involves two commercial fishermen: if they both overfish, but one of them does so with the intention of donating his surplus profit to charity, we would not and should not conclude that his behavior is morally permissible.

This would seem to be a nice utilitarian conclusion to the matter, but Young claims no allegiances. He seems to want to play all sides against one another, with the point being that neither from a utilitarian nor from a deontological nor from a virtue-ethical point of view will procreation come out looking any different, morally speaking, from overconsumption. He says:

Notice that this attempt [Dissimilarity B] to locate a relevant difference between [procreation and overconsumption] is not based on an intrinsic feature which one has and the other lacks, but on alleged differences in net utility; in other words, having children is likely to produce more good (or less bad) than an overconsumptive lifestyle, all things considered. In response, one could argue that the utilitarian theory upon which it is based is indefensible; therefore, though this may be a difference between the two, it is not a relevant difference. Obviously that response would satisfy non-consequentialists. Pursuing it, however, is not possible here, nor is it necessary; we can assume that some version of utilitarianism is defensible and still show that strategy B fails to locate a relevant difference (Young 2001, 187).

But his treatment of happiness is just as cavalier as his treatment of selfishness. Even assuming a utilitarian calculus, "Social scientists, as far as I know, have not proven that couples with children are - on the average - happier over the course of a lifetime than couples without children, or that offspring will experience or create more joy than sorrow in their lifetimes" (ibid.). Here Young combines the pollster's approach with a claim of non-quantifiability. We have not discovered that people who have children are on average happier than those without, and how could we? What metric of happiness would we or could we possibly use to decide such a thing? Young isn't playing fair. He offers up the absence of social-scientific evidence as though it had been asked for, and then implies that there would be no way to establish the desired conclusion through social-scientific study anyway. I suppose such evidence might seem germane to a utilitarian calculation, but then in that case why couldn't we assume the availability of an objective happiness metric, if we're being granted the assumption of a utilitarian ethics? Young would at this point need a general argument against the possibility of a workable utilitarian calculus, but this is something he just got done saying he doesn't need.

4 This would seem to weaken part of the basis of Young's own argument for ME, but never mind. 
In fact, his treatment of the good or happiness produced by procreation overlooks the obvious preference-utilitarian rejoinder that the happiness of procreation is of a higher or better quality than the happiness of overconsumption. In fact, given such conventional wisdom as "money can't buy happiness" and that children are worth more than material possessions, it's a wonder that Young doesn't even consider this sort of reply. Whether people do in fact prefer having children to having a lot of stuff could, one would think, be empirically investigated, but I doubt the results would be in Young's favor.

Of course it's everyone's right, at least in a democratic society, to decide for themselves what they believe to be good, beyond the thin theory that undergirds the politico-judicial edifice itself. ${ }^{5}$ This brings us to Dissimilarity C. Young argues that the vaunted right to procreate is something that has lately been called into question, and is hotly contested. He's right about this, of course; but here he had an overlooked opportunity to unify and bolster his entire case. The problem is that doing so in the way I'm about to suggest - the most natural way open to him given his analogical argument for ME - would reveal a fundamental weakness in his entire argumentative strategy.

Young wants to avoid committing himself to any particular ethical theory, which is sensible, but he also wants to locate the harms of procreation in its effects. As he says, "we must keep in mind that the environmental impact of the Grays' (or any couple's) having children will be much greater than the Greens' (or any childless couple's) being excessive consumers (no matter how outrageous); this is so because many of those children will reproduce (and many of them, etc.), resulting in an environmental impact far greater than what a childless couple could generate via eco-gluttony" (Young 2001, 188). There is quite obviously a tension here which can only be addressed by some theory of value. I will argue that the only way this could be done effectively without appealing to any specific ethical theory is at present simply unavailable.

\section{A Stronger Defense}

Young could have unified and strengthened his entire discussion of the dissimilarities as follows: he could have acknowledged that, in the minds of many people, procreation produces something - some utility, some kind of happiness, some good - that overconsumption does not and could not produce; but he could have argued that no form of value is an island, and that even our estimate of the value of procreation (or of consumption, or of overconsumption) is variable relative to our other values, in that the joys of any one of them, over the long run, produce diminishing returns.

The bottom line here is not simply the environment as such - as a bedrock value, or a bedrock of value - but environmental resources, children

5 If we assume, for the sake of argument, a Rawlsian point of view. 
included. 6 One of the harms that Young mentions arising specifically from procreation involves "population density, producing a variety of frustrations due to diminishing space, for example, overcrowded lakes, hiking trails, roadways, shopping malls, and backcountry" (ibid.). His concerns here seem almost prosaically poky (not to say liberal-bourgeois: crowded hiking trails?), but they actually go straight to the heart of his argument: that people, even our own children, (and hiking trails, for that matter) are not simply valuable for their own sake, whatever we may say or may think we believe, because the resilience of our capacity to experience anything as valuable rises and falls in relation to what economists call the "externalities" that the enjoyment of it produces. It's not just a question of uniqueness. Diamonds are highly valued in our society not because they are rare (which as a matter of fact they aren't), but because of what they are in our form of society. The same goes for children, or so Young could argue. ${ }^{7}$

This would have enabled him to defend his analogy while at the same time remaining neutral on the issue of ethical theory, and it would have provided him with a more effective reply to the counter-arguments he considers - from the selfishness of overconsumption relative to procreation, right through to the questions of rights and inherent moral value. The problem is that this strategy - though free of the taint and the limited appeal of any particular ethical theory - would of course require a defense of its own. It's not just that this isn't Young's main interest or concern in his essay; the defense I've proposed would support the analogy and would not require him to take any more of a stand than he does on its implications. Rather, the defense I've sketched implies something else: namely, that our estimate of the value of procreation can be amplified or diminished by our estimate of the likely quality of life of our offspring, relative to other factors. ${ }^{8}$ This seems to me to be the most natural way of defending Young's position, but this reveals a problem that can't be easily fixed.

6 It's not my intention to be reductionist about this - that what makes any environmental feature valuable is its utility or its capacity for commodification and eventual consumption. My point is simply that, if we reject inherent value, as Young seems to do, then the value of, say, a tree is relational, and is to be located specifically in the relation of trees to other living and non-living things and their multifarious movements.

7 This may sound cold. The love one has for one's children is said to be unconditional, though of course parents do sometimes disown their offspring. We have probably all had the experience of disappointedly relinquishing something we deeply loved because it became spoiled; and particularly awful are those cases in which the thing is spoiled by the very process of enjoyment itself. One really can have too much of a good thing. 8 This seems to be borne out by actual birthrates around the world. It's well known that families in "developed" nations have fewer children on average, but it also seems to be the case that birthrates generally rise and fall in relation to expectations for future prosperity - both at the family and at the national level. See, for instance, Modena et al. (2011); and Tendo and Meewalaarachchi (2009). 


\section{The Real Problem: How Many People Should There Be?}

What makes Young's argument so intriguing, and ultimately so revealing, is that it really just gives voice to an argument intuitively implied by the question: "How could you think of bringing a child into a world like this?" The only difference is that Young couches it specifically in terms of environmentalism. But given that people do in fact ask this question of each other in all seriousness, I find it surprising that Young's argument - or some version of it has not appeared sooner in the literature. What's useful in this argument, and in this question, from a moral-psychological point of view at least, is that it locates the blame for the bad effects of procreation as much in one's character as in the direct effect of one's actions on others. ${ }^{9}$

I myself have no children, and I have been accused on many occasions, sometimes by strangers, of being selfish for having no plans to have children. I've reached a point where I find the charge more puzzling and thoughtprovoking than insulting. My first inclination has always been to take a logical approach: since my children do not exist and (probably) never will, I could not be behaving selfishly toward them. How could I be? The charge of selfishness would seem logically to imply that I owe it to certain potential but non-actual people to produce them, which sounds on the face of it like nonsense. ${ }^{10}$ And of course the logical extension of this would seem also to imply that I've got a moral obligation to reproduce, which just raises even more questions and absurdities: am I morally obligated to produce as many people as I can, or only as many as I can responsibly support?

But this prompts more reflective consideration. Perhaps the point is that refusing to procreate implies something about $m e$ as a person; that I am lacking in some human virtue that I would do well to cultivate. I cannot so easily dismiss this thought. ${ }^{11}$ But then the question "How could you think of bringing a child into a world like this?" turns the tables. It's not just the diminished quality of life of your (potential) children that is morally relevant, and that the wrong of producing them lies solely in this. It also suggests something about you, both as a (would-be) parent and as a person. In fact, it

\footnotetext{
${ }_{9}^{9}$ This sounds, then, like a virtue-ethical argument; but this is just my starting point, not the destination.

${ }^{10}$ See Narveson (1967).

11 Of course I am well aware that all of this may be as much a matter of instinct and conformity as anything. People see someone without children and the evolutionarily ancient part of the brain thinks that this person is a threat to the survival of the tribe; hence the moral outrage. But this seems to me to be too easy. Whatever may psychologically or physiologically or evolutionarily motivate people to say that someone without children is selfish, they are in fact expressing a moral claim about the value of human life and one's attitudes toward it, whether or not they realize this. And I think this claim is worth exploring. Of course my interest in this is essentially philosophical. I don't plan on letting anyone talk me into having children. More on this below.
} 
would seem to imply that thinking of having children in a world like this would be selfish. Who would you benefit, other than yourself? This turns the accusation back on the accuser. At this point the question would seem to come down to who's got the more accurate view of the current and (likely) future state of things. ${ }^{12}$ But in fact the question of who benefits raises an even trickier question.

Derek Parfit (1984) makes the observation that "in a report of a U.S. Senate Commission on Population Growth and the American Economy, it is claimed that 'there would be no substantial benefits from the continued growth of the U.S. population.' This report never considers whether, if extra Americans were born, this might benefit these Americans" (Parfit 1984, 487). Could you benefit someone by bringing them into existence? To say that you can would seem to involve the same sort of absurdity as saying that I am being selfish to my non-existent children. But Parfit thinks that the claim that you can benefit someone by causing them to exist is defensible and not clearly absurd. Parfit claims that if we can judge parts of our lives as having or as not having been worth living through, then surely we can make the same sort of judgment about a whole life. And he thinks it's reasonable to say that a good life is better than nothing. This, he thinks, does not imply the absurd claim that if someone had not existed, this would have been worse for them. So we can say without absurdity that causing someone to exist can be a benefit to them, even though if they had never existed this could not have been a harm.

As John Leslie rightly observes: "whatever duties we have towards possible people are shrouded by philosophical mists, and the mists become particularly thick in the cases of those possible people who won't ever become actual" (Leslie 1996, 177). The conceptual issues involved in coming-to-be and going-out-of-being are deeply puzzling and would seem, at a minimum, to require ontological commitments of a kind that make the moral questions especially murky. If potential people can be said to have identities (in some sense), as Leslie claims, then we can presumably have direct duties of some sorts to these people. Leslie makes the intuitively plausible claim that "completely detailed descriptions can in theory be given of [potential people]."13 Indeed, he could, I think, get by with the weaker claim that the indirect or

\footnotetext{
12 I am going to assume for the purposes of this discussion - though the assumption may not be warranted - that whose view is more hopeful is not morally relevant. In my view, hope itself is only warranted relative to the reasonably expected state of things. This is essentially a prejudice, but I shall take it as a premise.

13 See Leslie (1996), ibid. If we take this claim really literally, as Jan Narveson (1967) does, then it starts to sound a lot less plausible; but this is, I think, to overlook its intuitive plausibility. Leslie perhaps goes too far in saying that we could give "completely detailed" descriptions of potential people, but as Parfit points out, you could secure a determinate reference to a non-actual person with a quite simple locution such as "the child I would produce with my spouse if we conceived one tonight," and this person's genetic identity at least could be precisely specified.
} 
indefinite identification of potential people can be quite enough to secure a moral or psychological claim, such as that I would have duties to and a special concern for my own children, whoever they are. This puts one in mind of the standard criticism of both traditional utilitarian and traditional deontological ethics to the effect that they are indifferent as to whose interests are being considered.14 Procreation isn't just the act of generating more people, after all. These people will not be strangers to you, but will of course be your children, by biological definition. And it seems reasonable to think that this carries some sort of moral weight.

But even this doesn't entirely remove the difficulty, or fully solve what Parfit called the Non-Identity Problem (Parfit 1984, 378). This is because, though it handles the identity part of the problem, it doesn't tell us which potential people ought to become actual (if any). Leslie thinks that the answer is: as many as would have happy lives. At the other end of the spectrum we have David Benatar (2006), who thinks that the answer to this question is: none. Parfit thinks that in order to correctly answer this question we would need what he calls Theory $X$ (ibid). Theory $\mathrm{X}$ is the theory of beneficence that will enable us to figure out how many people there should be relative to the prospects of a certain degree of quality of life for these people. This, in turn, will settle the question of how many people we should produce at a given point in time, and, indeed, ever.

One of the problems that Parfit discusses, having to do with our ability to make decisions of this sort, is what he calls The Down Escalator Case (Parfit 1984, 382-384). We can assume that, for some population of people, adding people over the short run will cause transitory good effects but will produce long-run bad effects within three generations - from resource depletion, overcrowding, and all of the other things Young mentions. The problem is that if people of the third generation choose a replacement rate of procreation over population growth, they will lose the transitory good effects of growth and their quality of life will immediately drop and will remain lower than it would otherwise have for the following three generations. But if they choose population growth over replacement, then eventually the transitory good effects of growth will be outweighed by the long-run bad effects and the quality of life will decline even below the point at which it would have been if the third generation had switched to replacement.

The real dilemma is this, however. Parfit notes that the solution to all this seems simple: growth for three generations followed by replacement in the fourth, when the long-run bad effects start to kick in. But, Parfit points out, no generation will be likely to willingly sacrifice the short-run good effects of growth and accept a lower quality of life for the sake of preventing a long-run

${ }^{14}$ See, in particular, Bernard Williams (1981). 
decline in the quality of life, particularly since the short-run effects will make it seem to each generation that the quality of life is just as high as it would otherwise have been with replacement starting in the first generation. This is therefore a choice that every generation must face, with growth as the most likely outcome, coupled with a long-run decline in the quality of life. As Parfit puts it, this is "an intergenerational Prisoner's Dilemma, of a kind in which it is least likely that those involved will achieve a solution" (Parfit 1984, 383).

This is ultimately the deepest strategic (and cognitive) problem with a moral argument like Young's. It's not just that this sort of arguments is "purely academic" and will therefore influence few people, or that even amongst those who would be convinced by it, their tastes will override their practical reasoning. The problem is much, much bigger than that. In fact, calling it a Prisoner's Dilemma as Parfit does isn't even entirely accurate. In a classic Prisoner's Dilemma, the effects of my actions on me and my compatriots are direct. The effects of procreation on quality of life are indirect and temporally diffuse. The intergenerational problem of the bad effects of procreation is a politico-economic sorites problem. The problem is not that I think to myself: "how will two more kids hurt anyone?" I know perfectly well that if everyone thought this way the effects would be worse for us all. But it's also not simply a straightforward Prisoner's Dilemma in which my aim is to attempt to maximize my own benefit, as in: "if only I could ensure that I get my two kids and that someone else goes without." I believe both that everyone has a right to their two kids and that if everyone has two kids we'll all be worse off. And I know that this last claim is true because I know that the incremental aggregate effect of universal procreation will be bad, though I also know that the bureaucratic administration of the global economic and social structures designed to support me and my two kids will spread out these effects (both spatially and temporally) and render them mostly invisible to me. As Michael Ignatieff (2000) and others have pointed out, it's easier to drop bombs on people you can't see by pushing a button than it is to shoot them when they're standing right in front of you.

\section{Conclusion}

The point is this: what Parfit's Down Escalator Case shows is that (1) our assessment of the value of procreation is relative to the effects it causes; but (2) our experience of these effects practically ensures that we will fail to properly estimate the value of population growth; and (3) to solve this problem rationally we would need a moral theory that could enable us to determine how many people there should be. This is what Young needs if he is going to defend his analogy effectively. No attempt to support his analogy that avoids these problems would be effective, but to address them adequately would require a theory we don't have. In his discussion of Dissimilarity D, Young challenges the 
claim that human beings have (or indeed that anything has) inherent value, but in that case it's hard to see how or why human interests, or really anyone's or anything's interests, should even matter in our assessment of the effects of procreation or population growth - or in our assessment of overconsumption, for that matter - unless we have some way of weighing relational value.

\section{Literature}

Assadourian, E. et al. 2004. State of the World 2004. New York: W.W. Norton.

Benatar, D. 2006. Better Never To Have Been: The Harm of Coming Into Existence. Oxford: Oxford University Press.

Hall, Ch. A. S., Pontius Jr., R. G., Coleman, L., \& Ko, J. 1994. “The Environmental Consequences of Having a Baby in the United States". Population and Environment 15 (6): 505-524.

Ignatieff, M. 2000. Virtual War: Kosovo and Beyond. New York: Picador.

Leslie, J. 1996. The End of the World: The Science and Ethics of Human Extinction. New York: Routledge.

Modena, F., Rondinelli, C., \& Sabatini, F. 2011. "Economic Insecurity and Fertility Intentions: The Case of Italy". Munich Personal RePEc Archive. Available from: http://mpra.ub.uni-muenchen.de/36353/.

Narveson, J. 1967. “Utilitarianism and New Generations”. Mind 76 (301): 62-72.

Parfit, D. 1984. Reasons and Persons. Oxford: Clarendon Press.

Tendo, M. \& Meewalaarachchi, S. M. 2009. "Socio-Economic Determinants Affecting the Demand for Children: The Pervasive Sense of Crisis in Japan". Meijo Asian Research Journal 1 (1): 77-83.

Williams, B. 1981. "Persons, Character, and Morality". In Wiliams, B. Moral Luck. Cambridge: Cambridge University Press: 1-19.

Young, T. 2001. "Overconsumption and Procreation: Are They Morally Equivalent?". Journal of Applied Philosophy 18 (2): 183-192. 
John Mariana (College of the Canyons)

\title{
Overconsumption, Procreation, and Morality
}

\begin{abstract}
Thomas Young (2001) argues that overconsumption and procreation are morally equivalent, and thus that anyone who disapproves of overconsumption must arrive at the same normative judgment concerning procreation (or procreation beyond a certain threshold). Young presents an analogical argument in support of his claim, and defends it against four varieties of objections intended to show that the analogy is weak or faulty. I argue that Young's defense of his argument fails, and that though a stronger case can be made for his claim of moral equivalence between procreation and overconsumption, a full defense of the claim would unfortunately require a moral theory that we presently do not have (namely, Derek Parfit's Theory X, the theory of beneficence that would tell us how many people there should be). This is unfortunate because in the absence of successful rational grounds for such a claim concerning the moral value (or disvalue) of procreation relative to resource consumption, we are likely to overlook or misjudge the moral and other costs of population growth.
\end{abstract}

Key Words: Population, population growth, overpopulation, overconsumption, environmentalism, procreation

Ethics in Progress (ISSN 2084-9257). Vol. 5 (2014). No. 1. pp. 52-65.

doi:10.14746/eip.2014.1.3 